\title{
REPRESENTAÇÕES EM CONSTRUÇÃO ENTRE IDOSAS E JOVENS EXPOSTOS A NOVAS PRÁTICAS SOCIAIS NA VELHICE
}

\author{
REPRESENTATIONS UNDER CONSTRUCTION BETWEEN ELDERLY WOMEN AND YOUTHS \\ EXPOSED TO NEW SOCIAL PRACTICES IN OLD AGE \\ REPRESENTACIONES EN CONSTRUCCIÓN ENTRE MUJERES MAYORES Y JÓVENES EXPUESTOS \\ A LAS NUEVAS PRÁCTICAS SOCIALES EN LA VEJEZ
}

\author{
Vannessa de Resende Cardoso Rabelo* \\ Angela Arruda ${ }^{* *}$
}

\begin{abstract}
RESUMO
Este artigo analisa representações sociais sobre o velho e o envelhecimento em dois grupos focais, um de idosas e outro de jovens, realizados em entidades que propõem atividades para essas faixas etárias em Juiz de Fora (Estado de Minas Gerais). Apoia-se na teoria de Moscovici e de Jodelet, e a análise, pelo software Alceste, identifica cinco classes. As classes características dos jovens trazem a figura do idoso de antigamente e de hoje, bem como a sabedoria da velhice. A classe típica das idosas aponta o medo da solidão e da dependência, bem como o desejo de autonomia. Já as demais apontam a falta de paciência e o desrespeito como um problema na relação da sociedade com os idosos. Em conclusão, os dados revelam, apesar da presença de representações hegemônicas, indícios de uma "nova velhice": a vinculação dos idosos à tecnologia, segundo os jovens; e a busca da autonomia, para as idosas.
\end{abstract}

Palavras-chave: Representações sociais. Velhice. Velho.

\begin{abstract}
This study analyzes social representations about elderly people and the aging process in two focus groups, one composed of elderly women and the other of youths. The investigation was performed in institutions that propose activities for these age groups in Juiz de Fora (State of Minas Gerais) and it is based on the Moscovici and Jodelet theory, and the analysis, using the Alceste software, identifies five classes. The characteristic classes of youths
\end{abstract}

\footnotetext{
Texto recebido em 29 de novembro de 2016 e aprovado para publicação em 20 de setembro de 2018.

*Doutora em Psicologia pela Universidade Federal do Rio de Janeiro (UFRJ), mestra em Gerontologia pela Universidade Católica de Brasília (UCB), psicóloga graduada pela Pontifícia Universidade Católica de Goiás (PUC Goiás). Endereço: Avenida Vice-Presidente José de Alencar, 1440, bloco 3, ap. 1201 - Jacarepaguá, Rio de Janeiro-RJ, Brasil. CEP: 22775-033. E-mail: vannessaresende@gmail.com.

"Doutora em Psicologia Social pela Universidade de São Paulo (USP), mestra em Psicologia Social pela Ecole des Hautes Études en Sciences Sociales, professora associada no Departamento de Psicologia Social da UFRJ e da Universidade de Évora. E-mail: arrudaa@centroin.com.br.
} 
bring the figure of the old ones in the past time and nowadays, as well as the wisdom of old age. The typical class of old women points to the fear of loneliness and dependence as well as the wish for autonomy. Other participants point out the lack of patience and disrespect as a problem in the relationship between society and the elderly. In conclusion, the data unveil, despite the presence of hegemonic representations, signs of a "new old age": the linkage of the elderly with technology, according to the youths; and the search for autonomy, for old women.

Keywords: Social representations. Old age. Elderly.

\section{RESUMEN}

Este artículo analiza representaciones sociales sobre el viejo y el envejecimiento en dos grupos focales, uno de ancianas y otro de jóvenes, realizados en entidades que proponen actividades para estos grupos de edad, en Juiz de Fora (Estado de Minas Gerais). Se apoya en la teoría de Moscovici y de Jodelet, y el análisis, a partir del software Alceste, identifica cinco categorías. Las categorías características de los jóvenes traen la figura del anciano de antiguamente y de hoy, así como la sabiduría de la vejez. La clase típica de las mayores apunta el miedo a la soledad y a la dependencia, así como el deseo de autonomía. Las demás apuntan a la falta de paciencia y la falta de respeto como un problema en la relación de la sociedad con los adultos mayores. En conclusión, los datos revelan, a pesar de la presencia de representaciones hegemónicas, indicios de una "nueva vejez": la vinculación de los mayores a la tecnología, según los jóvenes; y la búsqueda de la autonomía para las ancianas.

Palabras clave: Representaciones sociales. Vejez. Viejo.

\section{INTRODUÇÃO}

E ste trabalho apresenta alguns resultados de uma pesquisa de doutorado sobre as representaçóes sociais do envelhecimento, da velhice e do velho na mídia impressa e em grupos focais de idosas e jovens de Juiz de Fora, Estado de Minas Gerais, Brasil. Traremos aqui somente o recorte contendo a fala dessas idosas e jovens.

Atualmente se discute o impacto do envelhecimento populacional em diversos âmbitos. Gerontólogos apontam a problemática do boom de idosos na sociedade, no sentido de alertar sobre a urgência de políticas públicas que atendam à população idosa com mais qualidade e trabalhem a família e a sociedade para essa nova realidade (Rodrigues \& Rauth, 2006). Pesquisas na área da Gerontologia 
e da Geriatria trazem novos conceitos e vêm desmistificando ideias errôneas em relação ao processo do envelhecimento e à velhice (Caldas, 2006; Neri, 2001).

O envelhecimento da população mundial é um fenômeno novo ao qual mesmo os países mais ricos e poderosos ainda estão tentando se adaptar. O que era no passado privilégio de alguns poucos passou a ser uma experiência de um número crescente de pessoas em todo o mundo (Kalache, Veras, \& Ramos, 1987, p. 201).

NoBrasil, "avelocidadedoenvelhecimentopopulacionalserásignificativamente maior do que ocorreu nas sociedades mais desenvolvidas no século passado" (Caldas \& Veras, 2012, p. 70). Nos últimos anos, o número absoluto de pessoas com mais de 60 anos aumentou nove vezes, saltando de 1,7 milhões de idosos, em 1940, para 14,5 milhões, em 2000. A previsão é que, em 2020, 30,9 milhões terão 60 anos (Camarano, 2004). Segundo Rodrigues e Rauth (2006), em 2020, serão quase 44 idosos por grupo de 100 pessoas em idade produtiva. Para esses autores, as rápidas mudanças sociais, científicas e tecnológicas desafiam a capacidade de adaptação e previsão das instituições sociais e dos indivíduos.

O cenário social brasileiro está passando por uma nova configuração devido à modificação na pirâmide populacional. A diversidade de informação e as mudanças interferem na forma de comunicação e de relacionamento sociofamiliar. O envelhecimento da sociedade trará mudanças culturais que já estão começando. Segundo Arruda (2012), a velhice é uma novidade no Brasil, tanto para cada indivíduo quanto para a sociedade brasileira como coletividade, acostumada a se pensar como "país jovem", e está em vias de ser elaborada por meio das representações sociais.

O preparo da sociedade para o novo panorama social não consiste apenas em estabelecer as políticas públicas necessárias. Envolve também novas práticas sociais e repaginação das representações sociais. Mais do que temer o que está previsto, é preciso que o conceito de velhice seja reformulado: os papéis sociais do velho necessitam ser ampliados e considerados (Hillman, 2001).

Apesar da existência de propostas de políticas públicas, intervenções em instituiçôes de longa permanência para idosos (ILPI), cursos para cuidadores e profissionais que lidam com o idoso na vida diária, ainda persistem as representações sociais negativas sobre o envelhecimento, o velho e a velhice, oriundas de um processo histórico e sociocultural para o qual contribuíram a mídia, os âmbitos sócio familiares e alguns meios acadêmicos, insistindo na imagem do país do futuro. 
Estamos, portanto, diante de uma provável e necessária reformulação do senso comum referente ao envelhecer no Brasil. Para Arruda (2012, p. 23), "Quando um tema provoca posicionamentos e afetos diferentes, cria debate e controvérsia" e pode se "transformar em representação social, ou seja, pode receber elaboraçôes variadas de grupos variados". Isso vai ao encontro do pensamento de Moscovici (2007, p. 95), de que "o senso comum está continuamente sendo criado e recriado em nossas sociedades", levando em conta inclusive a contribuição do conhecimento científico e tecnológico que circula como parte do caldeirão de ideias que contribuirão para seu redesenhar.

Dessa forma, diante da emergência do tema na atualidade, as representações sociais sobre o envelhecimento e a velhice estariam em pleno processo de elaboração. E é importante saber como isso acontece hoje, mesmo se este trabalho é apenas uma pequena aproximação a essa problemática.

A teoria das representações sociais de Moscovici (2012) foi a base teórica desta pesquisa, considerando que estamos diante de um movimento do pensamento social que se expressa desde os pequenos grupos até o conjunto da sociedade, num intenso processo de comunicação social que gera reformulações, negociações e controvérsias, de forma heterogênea e não linear, no conjunto da população.

A elaboração das representações sociais passa por dois processos principais: a ancoragem e a objetivação. A ancoragem consiste em transformar algo estranho que nos perturba ou intriga "em [acordo com] nosso sistema particular de categorias e o compara com um paradigma de uma categoria que nós pensamos ser apropriada" (Moscovici, 2007, p. 61). A objetivação diz respeito ao processo de materializar uma abstração. Essa é uma artimanha do ser humano ao reproduzir um conceito em uma imagem. Objetivar é unir a não familiaridade com a realidade, por meio de uma concretização do abstrato.

No processo de elaboração das representaçôes sociais sobre o velho, velhice e envelhecimento, os grupos vão ancorar naquilo que é conhecido e objetivar o que ainda não é compreensível, tornando o abstrato em concreto. $\mathrm{O}$ "alarme" do fenômeno do envelhecimento para o Brasil, especificamente para Juiz de Fora, acarreta a necessidade de transformar o não familiar em familiar. Isso implica, ao mesmo tempo, defrontar-se com as representações hegemônicas existentes sobre o tema; aquelas que atravessam um conjunto organizado como uma nação, cidade ou outro, passando de geração em geração, com forte apelo afetivo (Moscovici, 1988).

Por que investigar em Juiz de Fora? De acordo com Magalhães (2007), a população juiz-forana de 60 anos ultrapassa a média nacional. Na cidade, essa é a faixa etária que mais cresceu em dez anos. Dados do Censo do IBGE 
(2010, apud Universidade Federal de Juiz de Fora, 2012) revelam que o avanço superou as médias estadual (42\%) e nacional (41\%). Ademais, Juiz de Fora vem realizando projetos direcionados à terceira idade, por meio de várias entidades governamentais e da sociedade civil. Pesquisa realizada entre 2010 e 2013 mostrou que há toda uma atenção voltada para a essa população na cidade (por exemplo, nas audiências públicas promovidas pela Comissão Especial do Idoso na Câmara Municipal de Juiz de Fora e nas reuniōes do Conselho Municipal dos Direitos do Idoso) (Rabelo, 2014). Mas, considerando o novo contexto nacional já explicitado, como é entendido o envelhecimento nessa cidade? Buscando responder a essa pergunta, o objetivo deste artigo é analisar as representações sociais de idosas e de jovens sobre o envelhecimento, velhice e velho na cidade de Juiz de Fora.

\section{METODOLOGIA}

\subsection{Produção dos dados}

Esta é uma pesquisa qualitativa, que utilizou grupos focais como método de coleta de dados. Segundo Morgan (1997), o grupo focal é uma técnica que permite a interação grupal, com base em um tema determinado pelo pesquisador. Em pesquisas sobre representações sociais, esse método tem sido amplamente utilizado, como apontam Nóbrega, Andrade e Melo (2016). Ele capta processos e conteúdos cognitivos, emocionais, ideológicos, representacionais mais coletivos, menos idiossincráticos e individualizados, como aponta Gatti (2005).

Foram montados dois grupos focais: um com mulheres idosas e outro com jovens. Grupos focais contam, em geral, com um número de 4 a 10 participantes, pois grupos grandes tendem a diminuir a possibilidade de participação efetiva de todos (Gondim, 2003). Um grupo ficou restrito a idosas porque nenhum homem teve interesse em participar das sessões. Foram oito mulheres, frequentadoras do Sesc, com a média de idade de 66,5 anos. A maioria tinha graduação (5) e era viúva (5). A renda familiar foi: menos de 2 a 5 salários mínimos (5 idosas), entre 5 e 10 ( 2 idosas) e mais de 10 ( 1 idosa). O outro grupo teve 7 jovens $(2$ homens e 5 mulheres), alunos do Senac, com ensino médio e média de idade de 22,3 anos. Deles apenas dois estabelecem contato com os idosos, por meio de atividades e, ou, associação. A renda familiar foi de menos de 2 até 5 salários mínimos ( 5 jovens), entre 5 e 10 (2). Ou seja, este grupo tem menor escolaridade e menos renda que o de idosas. Essas instituições fizeram parte da observação de campo para o doutorado, que revelou seu interesse. O Sesc promovia eventos para grupos de idosos: esportes, cultura e educação, com um movimento incipiente 
de informação sobre a fase da velhice. Assim, a escolha de participantes dessas atividades se valia do hábito da conversa em grupo. Adotaram-se os critérios de idade acima de 60 anos, capacidade cognitiva e de saúde física das senhoras.

O Senac tinha um programa de inclusão social e profissional chamado Jovem Aprendiz, com alunos entre 14 a 24 anos. Os critérios de seleção foram: idade a partir de 19 anos, baseado no Estatuto da Criança e do Adolescente (ECA), que delimita a adolescência entre 12 e 18 anos, e o interesse dos jovens em discutir questôes sobre o envelhecimento. Realizou-se um treinamento prévio de uma observadora pela pesquisadora. O questionário foi elaborado com base na observação de campo, pesquisa de jornais e experiência profissional da primeira autora.

Foram realizadas três sessóes de cerca de 60 minutos com cada grupo, para cobrir a temática de forma ampla e adequada. Todos os encontros foram coordenados pela pesquisadora, acompanhada da observadora, que os registrava por meio de filmagem e gravação em MP3. As sessões incluíam perguntas sobre a velhice (por exemplo, o que há de bom e de ruim nela) e sobre o velho (por exemplo, como ele era ontem, como é hoje e como será amanhã, que problemas enfrenta na cidade). O grupo de idosas respondeu a perguntas específicas (por exemplo, como é viver a velhice e qual é o maior medo que ela traz). Já os jovens responderam, ainda, a perguntas como: qual relação mantém com velhos, se tem medo de envelhecer e como se imaginam na velhice. Ambos os grupos responderam a um questionário sociodemográfico.

O projeto de pesquisa foi aprovado Comitê de Ética em Pesquisa da Escola de Enfermagem Anna Nery/Instituto de Atenção à Saúde São Francisco de Assis, da Universidade Federal do Rio de Janeiro (UFRJ). Todos os participantes assinaram o termo de consentimento livre e esclarecido, que informava garantir o anonimato dos participantes.

\subsection{Procedimentos de análise dos dados}

As transcrições das sessões passaram pela análise léxica realizada pelo programa informático Alceste (Análise Lexical por Contexto de um Conjunto de Segmentos de Texto), por meio do tratamento estatístico de seus elementos (Oliveira, Gomes, \& Marques, 2005). O programa agrupa as ocorrências das palavras contidas nas unidades de contexto inicial (UCI) fornecidas pelo pesquisador, em conforme as raízes dos vocábulos (formas reduzidas das palavras), e calcula a frequência destas (Camargo, 2005). Divide o texto em trechos com um número médio regular de palavras, denominados unidade de contexto elementar (UCE). Nessa 
etapa, é feita a classificação de acordo com os respectivos vocabulários das UCE, e seu conjunto é repartido conforme a frequência das formas reduzidas. Formas reduzidas e UCE são cruzadas e, por fim, chega-se à classificação hierárquica descendente (CHD). Cada classe reúne UCE com vocabulário específico. $\mathrm{Na}$ etapa seguinte, a descrição de cada classe é produzida principalmente pelo seu vocabulário característico (léxico) e pelas suas variáveis. Na última etapa, o programa calcula e fornece as UCE mais características de cada classe. Assim, é possível a contextualização do vocabulário típico de cada classe.

Nesta pesquisa, as transcriçóes de cada grupo focal representaram uma unidade de contexto inicial (ou seja, o grupo jovem correspondeu a uma UCI; e o grupo idoso, a outra), tendo sido essas (os dois tipos de grupo) as únicas variáveis consideradas. ${ }^{1}$

\section{RESULTADOS E DISCUSSÃO}

O processamento das sessões de grupo focal pelo Alceste teve $78 \%$ de aproveitamento do corpus, organizado em 793 UCE (segmentos). A classificação hierárquica descendente forneceu cinco classes. Numa primeira partição, o corpus foi divido em dois. De um lado, o programa reuniu as classes 2 e 3 . Numa nova partição, o resto do corpus separou a classe 1 das classes 4 e 5 . Nas classes 1 e 4, o grupo de jovens foi identificado como variável, ou seja, estes são os sujeitos que mais as caracterizam. Já o grupo de idosas foi destacado na classe 3 . As classes $2 \mathrm{e}$ 5 não apresentaram variável, podendo ser combinações de léxicos disseminados nos dois grupos.

No dendrograma a seguir (figura 1), incluiu-se o título atribuído a cada uma das classes, a variável encontrada, o número de UCE que a compõe, o número de palavras e a porcentagem de UCE da classe em relação ao total. Com base neste dendrograma, parecem estruturar-se dois campos representacionais: o primeiro, construído pelas classes 1, 4 e 5 (denominado de "Localizando o idoso na nossa sociedade"), tendencialmente do grupo jovem; e o segundo, pelas classes 2 e 3 (denominado de "O que é ser velho"), tendencialmente das idosas.

\footnotetext{
${ }^{1}$ Cada grupo (idoso e adulto-jovem) foi separado por linhas com asteriscos, que indicam sua característica, única variável que foi considerada: ${ }^{* * * * *}$ gru_jov e ${ }^{* * * * *}$ gru_ido
} 
Figura 1 - Dendrograma: classificação hierárquica descendente efetuada pelo programa Alceste

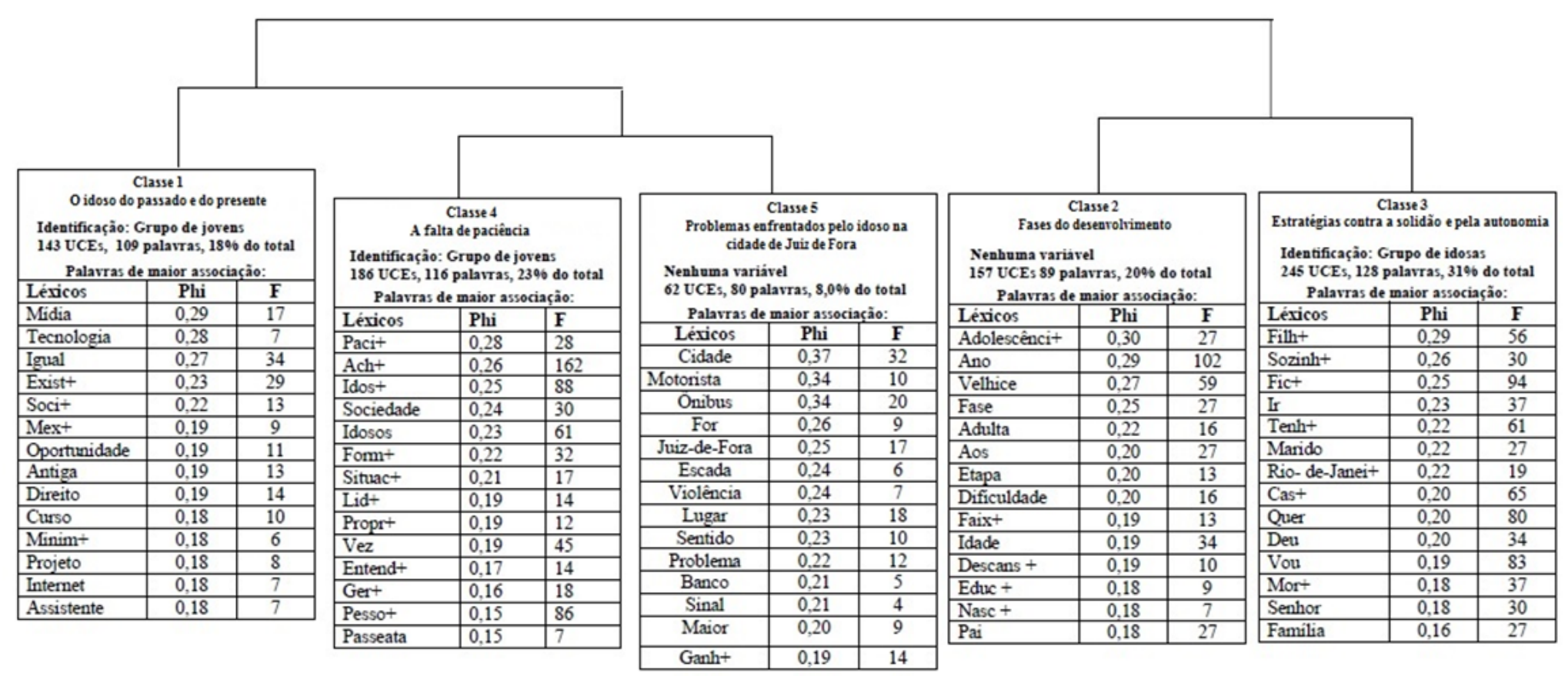

Fonte: elaborado pelas autoras. 


\subsection{Localizando o idoso na sociedade (classes 1, 4 e 5)}

As classes 1 , 4 e 5 revelam a necessidade de localizar o idoso na sociedade atual. A tecnologia e a oferta de atividades e recursos sociais para a população idosa contribuem para a formação das representações dos jovens pesquisados sobre o envelhecimento. As diferenças geracionais e os problemas urbanos e sociais enfrentados pelos idosos mostram a elaboração de uma nova dinâmica das relaçôes e compreensão do papel do idoso na modernidade. A discussão dessas classes como integrantes de um mesmo campo compreenderá cada variável encontrada pelo programa, a proporção das UCE, os léxicos mais significativos e as principais UCE encontradas.

\subsubsection{Classe 1: o idoso do passado e do presente}

Na classe 1 (18\% das UCE), "O idoso do passado e do presente", o grupo de jovens tem o discurso predominante. Os léxicos mais significativos são mídia, tecnologia, igual, exist+, socie+, mex+, oportunidade, antiga, direito, curso. A principal diferença entre o idoso de antigamente e o de hoje é o acesso à mídia e o uso da tecnologia. "Hoje em dia, [o idoso] aprende a mexer no computador, vê a importância de fazer outras línguas, mexer no computador, aprender a usar o celular, porque antigamente não tinha isso" (UCE 115, grupo jovens).

Segundo esses jovens, antigamente, também não havia grupos de convivência que promovessem distração e exercícios físicos. Hoje os idosos são mais independentes, e a atividade física possibilita que eles vivam mais: "Existem programas, coisas novas para os idosos fazerem. Praticamente, dança é uma coisa que muita gente gosta e os idosos estão frequentando" (UCE 211, grupo jovens).

Os direitos dos idosos são uma luta a ser enfrentada por essa faixa etária, mesmo que muitos deles não saibam manipular a tecnologia de comunicação mais avançada.

Nem toda a população, às vezes, tem acesso às redes sociais. Igual à minha mãe, o meu pai, eles não mexem no computador. Mas se mostrar no telejornal, se for na televisão: "A gente quer isso, a gente quer lutar por isso", então eu acho que a mídia é um meio de comunicação que eles deveriam estimular para conseguir seus direitos. (UCE 394, grupo jovens).

Essa classe contrapõe a imagem estereotipada do passado, a outra, atual: "Então, a tecnologia, a inovação, estão aqui para a gente deixar de ter aquele estereótipo do velhinho de cabeça branca que faz tricô" (UCE 431, grupo jovens).

Mesmo os idosos sendo mais lentos, mais frágeis, alguns se esforçariam para acompanhar a tecnologia. Aparecem, portanto, diferentes velhices: há idosos 
mais ativos e menos ativos. $\mathrm{O}$ grupo compartilharia duas representações sociais da velhice (ativa e lenta) que circulam na sociedade. O velho que faz atividades é reconhecido positivamente. A ambiguidade quanto à velhice, ao idoso, aparece em outras pesquisas com o mesmo grupo etário, às vezes identificada como negatividade e positividade, ou perdas e ganhos (Pereira, 2012; Freitas \& Ferreira, 2013; Santos, Tura, \& Arruda, 2013).

\subsubsection{Classe 4: a falta de paciência}

Na classe 4 (23\% das UCE), a falta de paciência das pessoas aparece como uma das causas dos problemas enfrentados pelos idosos, para os jovens pesquisados. Os léxicos mais significativos foram: paci+, ach+, idos+, sociedade, idosos, form+, situac+e lid+. O léxico idoso está associado à sociedade. Vê-se a necessidade de mudança desta em relação aos idosos.

Acho que é a falta de paciência que é o pior fator que eles enfrentam, a discriminação e o preconceito mesmo que as pessoas têm. Eu acho que eles são idosos, eles não vão entender, eles não vão conseguir mais fazer isso. Às vezes, também vão fazer um curso e fala: nossa, mas está velho e vai fazer um curso? (UCE 369, grupo jovens)

A falta de paciência aqui caracteriza o idoso como uma pessoa lenta, com dificuldade de entender o que os jovens comunicam. Trata-se de uma objetivação, forma que configura uma representação a partir do recorte e recomposição de características do objeto numa determinada imagem que o simplifica, baseada na perspectiva de quem fala (Jodelet, 2001), podendo provocar desvalorização, diferenças de tratamento e outros problemas nas práticas sociais de profissionais que lidam com eles e da sociedade em geral.

Os discursos dos jovens sugerem que a questão do ritmo, do tempo, para alguns, seria um ponto-chave da representação social e da construção da relação deles com os idosos, já que as duas geraçôes vivem temporalidades diferentes.

Ele agora está descansando. E também não tem aquela virilidade para ter aquela mesma disposiçãa que você, ter o mesmo ritmo que você. Isso reflete muitas das vezes, até na forma de falar. Às vezes, ele fala até mais devagar, pausadamente, demora para contar um caso e vai, você não (UCE 76, grupo jovens).

Esse discurso sinaliza a falta de paciência como divisória entre "nós" (os jovens) e "eles" (os idosos) A impaciência materializa a dificuldade que essas diferenças provocam, objetivando essa relação ao enxugar sua complexidade para torná-la algo palpável (Moscovici, 2012). Os dados também apontam que, para alguns jovens, o bom envelhecimento é fruto apenas do esforço individual: bastaria 
investir na própria saúde: "Eu acho que você determina a maneira que você vai envelhecer, de várias formas. Observando a alimentação, fazendo exercícios físicos, mas também o que diz respeito a suas emoções" (UCE 92, grupo de jovens).

Estariam esses jovens propondo, na perspectiva individualizante que se exacerba na atualidade, seu próprio programa de preparação para o envelhecimento? A fala desse grupo pode sofrer influência do que é divulgado pelos meios de comunicação. Silva (2008, p. 806) destaca que, por meio da identidade "terceira idade", a vivência do envelhecimento parece:

Depender quase que exclusivamente do engajamento e da disciplina de cada indivíduo em fazer de sua velhice um momento de atividade e recriação, seguindo adequadamente as prescrições médicas e os modelos sociais, estéticos e afetivos que compõem o referido estilo de vida da terceira idade, e vêm sendo intensamente divulgado nos meios de comunicação.

\subsubsection{Classe 5: problemas enfrentados pelo idoso na cidade de Juiz de Fora}

Na classe 5 (8\%, a menor proporção de UCE), são abordados os problemas que o idoso enfrenta na cidade de Juiz de Fora, sem destaque de um ou outro grupo. Seus principais léxicos são cidade, motorista, ônibus, Juiz de Fora, escada e violência. Dois problemas centrais são apontados nas UCE: a violência e o desrespeito ao idoso e a suas demandas.

A violência aparece como um problema atual da cidade nas falas de idosas. Algumas demonstram a necessidade de encontrar uma solução e a falta de confiança nos governantes.

Agora está tendo violência, tendo problema. As autoridades, porque você não pode confiar. Vou eleger esse prefeito. Aí vem esse daqui. Eu vou eleger porque ele vai resolver esse problema. Isso ninguém vai resolver. Ninguém, nem o governo daqui, nem São Paulo, nem do Brasil, nem o presidente da República, ninguém vai resolver (UCE 726, grupo de idosas).

Já na fala de alguns jovens, a violência está em todo lugar: "Eu acho que não é questão de Juiz de Fora. No caso, nenhuma cidade, pode ser a menor ou a maior que for, que tudo tem problemas, tudo tem violência, tudo tem dificuldade" (UCE 200, grupo de jovens).

A adaptação da cidade às demandas do idoso ressalta, nessa classe, outro aspecto em elaboração no novo contexto social: a mobilidade urbana. Os problemas aparecem nos conflitos gerados na prática cotidiana, acentuadamente 
no transporte coletivo, o desrespeito do motorista de ônibus, e nas filas de atendimento preferencial:

Eles não respeitam. Eles não estão nem aí. Os motoristas de ônibus, eles fazem questão de parar longe do meio fio e ri ainda, zombam ainda, chamam de jacaré (UCE 592, grupo de idosas).

Eu me pergunto até que ponto um idoso consegue se adaptar a uma cidade como essa, que um idoso vai se adaptar a prédios que não têm elevador (UCE 811, jovens).

Apesar dos problemas apontados pelas idosas, elas reconhecem que a cidade pode oferecer algo de bom, como lugar para se envelhecer: "Você tem aqui em Juiz de Fora uma cidade prática. Você tem ônibus que te leva de bairro a bairro. Uma cidade prática para andar. Ela ajuda muito as pessoas a buscarem suas necessidades de andar pela cidade" (UCE 755, grupo de idosas).

A ausência, para os jovens, de aspectos positivos para os idosos em Juiz de Fora poderia sinalizar a dificuldade de localizar o idoso no novo contexto social. Talvez ele ainda não seja um personagem inserido na paisagem urbana, para esses jovens. Isso seria indício de uma representação ainda em construção nesse grupo? Segundo Ferreira (2016, p. 33), apesar do conhecimento do envelhecimento dos processos cognitivos, no Brasil, os estudos sobre suas consequências na mobilidade urbana dos idosos são "recentes, regionalizados e escassos de informação".

\subsection{O que é ser velho (classes 2 e 3 )}

Os dados encontrados nas classes 2 e 3 trazem a definição de como é ser velho e o que a sociedade espera dessa fase, mostrando indícios de uma nova representação em construção.

Como no conjunto de classes anterior, estas classes serão discutidas mostrando cada variável encontrada, a porcentagem das UCE, os léxicos mais significativos e as principais UCE.

\subsubsection{Classe 2: fases do desenvolvimento}

A classe 2 é relativa às fases do desenvolvimento humano (20\% das UCE, posição intermediária entre as duas com maior e as duas com menor proporção de UCE). Os léxicos mais significativos foram: adolescênci +, ano, velhice, fase, adulta e dificuldade. Para esta classe, o programa não identificou um grupo predominante como variável. 
Suas UCE mostram que as fases do desenvolvimento humano são etapas do crescimento em que se vão adquirindo a maturidade, a sabedoria e a experiência, e aparecem na fala de idosos e jovens:

O conhecimento na vida da gente começa desde quando a gente nasce, vai crescendo passa pela infância, passa pela adolescência, pela juventude, vem a maturidade, vem a velhice (UCE 485, grupo de idosas).

Eu particularmente não tenho medo de envelhecer, porque eu procuro focar mais nos benefícios que a velhice pode me trazer, como experiência, amadurecimento, tranquilidade, descanso (UCE 342, grupo de jovens).

Tais aspectos surgem nos dois grupos como ganhos na fase da velhice, o que coincide com outras pesquisas sobre representação social do envelhecimento (Percora, Anjos, \& Paredes, 2010; Santos, Tura, \& Arruda, 2013; Wachelke et al., 2008).

Então a sabedoria vem depois do discernimento. Você tem na sua vida a sabedoria. Aquelas coisas que você pode dar fôlego, tudo bem. Aquelas que você não pode, você aceita. No meu caso, é aquilo que eu coloquei: a sabedoria, a experiência e a alegria de viver (UCE 799, grupo de idosas).

No entanto, em ambos os grupos, observou-se a dificuldade de situar cronologicamente o início da adolescência, vida adulta e velhice. A idade cronológica sozinha não diz muito sobre o real envelhecimento, pois deve considerar-se a heterogeneidade do envelhecer. $\mathrm{O}$ processo do envelhecimento é multifatorial (Caldas \& Veras, 2012). Pode-se entender que essa dificuldade também seja representativa dessa "nova era", já que, atualmente, grupos que trabalham com idosos se apropriam de diversas terminologias para definir a fase da velhice, como "terceira idade" ou "melhor idade".

Silva (2008), referindo-se à inovação em relação à identidade da velhice, considera que as imagens relacionadas ao envelhecimento eram descanso, quietude, inatividade. $\mathrm{Na}$ Contemporaneidade, contudo, inclui-se aí o estímulo à atividade, à aprendizagem, à flexibilidade, à satisfação pessoal e à formação de vínculos afetivos inéditos. Para a autora, essa caracterização da "terceira idade" propõe uma nova identidade da velhice. Seu surgimento representa uma negação social da velhice propriamente dita.

Neste estudo, observamos uma imagem da velhice jovem, que seria aquela ativa e moderna para o grupo de jovens. Ela é reforçada pela mídia e contribui para a cobrança social de uma aparência jovem. Castro et al. (2016), em pesquisa com mulheres que adotam práticas de rejuvenescimento, mostra que rugas e fios 
brancos "são associados ao desleixo, como algo feio que pode ser embelezado" (p. 323). A aparência jovem se torna uma forma de negar a velhice e seus sinais, contribuindo para a imagem do bom envelhecimento.

\subsubsection{Classe 3: estratégias contra a solidão e pela autonomia}

A classe 3 corresponde à de maior poder explicativo (31\% de UCE). Seus léxicos mais significativos foram: filh+, sozinh+, fict, ir, tenh+, marido e rio-dejanei+. Ela parece indicar como as idosas fazem para preencher o tempo, escapar da solidão.

Meu marido disse que é para eu preencher meu tempo. Mas preencher o meu tempo, eu posso ir à rua, dar uma volta, olhar loja. Eu estou sentindo que eu estou precisando mesmo. Eu estou frequentando grupos, que eu estou sentindo a necessidade de frequentar (UCE 840 , grupo de idosas).

Também aponta o protagonismo das idosas ante o desejo de manter sua autonomia. A possibilidade de pagar uma clínica para idosos ou adaptar a casa para as novas necessidades aparece como uma alternativa para algumas.

Se eu tiver que depender, eu já falei, vou para uma clínica. Eu tenho condição de pagar. Eu pago a clínica, pago acompanhante. Não quero depender de ninguém, disso, daquilo, de fulano, de sicrano, porque eu tenho uma festa pra ir e eu não posso (UCE 810, grupo de idosas).

Preservar a independência pode ser uma manifestação de amor à liberdade: "Eu vou para o Sírio-Libanês, pago para entrar lá, e se ninguém me tira para dançar. Eu danço sozinha, numa boa” (UCE 982, grupo de idosas).

Essas falas parecem expressar uma forma de exorcizar o temor que a solidão e a dependência provocam nessas mulheres, detentoras de meios que possibilitam uma razoável autonomia. Também destacam a idosa se transformando em ator social, papel antes não esperado pela sociedade.

Eu fiquei sozinha na minha casa. Eu fiquei seis meses. Seis meses após uma cirurgia. Eu não podia nem dirigir. Eu não fiquei nada de depressão, não. Ia no computador, não dava conta, ia fazer um bordado, não dava conta, deitava na minha cama. Às vezes, ligava para uma pessoa (UCE 631, grupo de idosas).

Observa-se, ainda, nessa classe, a tensão entre a solidão e a autonomia, mediada pela proatividade para vencer a primeira e afirmar a segunda. "Eu quero ir embora para o Rio de Janeiro. Não quero mais ficar aqui. Minha família mora 
toda lá. Em virtude do meu casamento, minha família foi toda para lá" (UCE 960, grupo de idosas).

Dados sobre declínio e dependência podem ser encontrados em outras pesquisas. Sousa, Farias, Doula e Mafra (2016) analisaram as representaçôes sociais sobre o ser idoso, o envelhecimento e a velhice entre participantes do Programa Municipal da Terceira Idade (PMTI) de Viçosa, Minas Gerais. Eles constataram uma representação negativa associada tanto à perda da saúde quanto ao declínio e dependência que se manifestam na velhice. Isso reforça a maneira como o idoso se vê e possivelmente contribui para a tensão entre solidão e a autonomia.

Contarello, Leone e Wachelke (2012) tentam traçar uma síntese de estudos sobre o envelhecimento, no contexto italiano. Uma de suas conclusões é sobre duas perspectivas contrastantes sustentadas por Beauvoir (1990): a de dentro e a de fora. O olhar externo é como a velhice se apresenta ao outro e o interno, como é vivida pelos protagonistas:

Quanto mais externa é a perspectiva, mais o envelhecimento aparece escuro e ameaçador, caracterizado por perdas dolorosas, principalmente em termos de atividades (física e sexual, sobretudo nos homens) e por vida emocional (com aspectos de vazio, arrependimento, melancolia, particularmente nas mulheres) (Contarello, Leone, \& Wachelke, 2012, p. 156).

Os idosos entrevistados por esses autores "denunciam esse núcleo de significados, que poderíamos resumir no leitmotiv - quase um mantra - 'é ruim ficar velho"' (Contarello, Leone, \& Wachelke, 2012, p. 156).

Para os jovens participantes desta pesquisa em Juiz de Fora (num olhar de fora), hoje em dia, ser idoso parece não ser tão ruim. Os idosos têm mais interação, atividade física. Parece ser uma maneira mais contemporânea de ver o idoso, ancorando-o à tecnologia. As próprias idosas (o olhar de dentro) não aderem claramente ao mantra negativo. Até que ponto isso se relaciona ao contexto brasileiro, em contraste com o italiano, e ao dos nossos pesquisados em particular (a condição socioeconômica e de gênero das idosas, no caso), contudo, não é possível afirmar sem um levantamento como aquele realizado pelos colegas. 


\section{CONSIDERAÇÕES FINAIS}

Pela análise dos dados, podem-se considerar indícios de mais de uma representação social do idoso e do envelhecer. Se, por um lado, ambos os grupos apresentam um indicador de que uma "velhice jovem" faz parte dessa nova era, os jovens a localizaram no contexto da tecnologia, enquanto as idosas, frequentadoras do Sesc, no das práticas que reforçam a autonomia e a interação. A comunicação, portanto, tem lugar importante, mas sob formas diferentes, segundo o grupo.

Esses jovens falam de sua própria experiência com os idosos ao assinalar o contraste do ritmo de vida e da temporalidade das duas gerações, remetendo, de certa forma, à antiga representação hegemônica (Moscovici, 2000) do idoso.

O ritmo talvez seja o cerne desta representação: para lidar com o idoso, é preciso munir-se de paciência, contrariando o ritmo da geração filha da tecnologia. A resposta desses jovens (e talvez da sociedade em geral) objetiva-se na impaciência, exemplificada pelo descaso do motorista de ônibus pelo idoso que lhe faz sinal. Espera-se que o idoso cumpra sua parte, adaptando-se às condiçôes da vida atual: usar as novas tecnologias para a comunicação; conviver com seus pares; exercer seus direitos; circular na cidade, mas sem perturbar quem vive a correria e o cansaço da vida urbana. O estereótipo da cabeça branca, do tricô é substituído pela figura do idoso "antenado", que dança, comunica-se e se encontra com amigos, amigas, cria seu percurso na cidade, sem contrariar o tempo da urgência. Ou seja, uma velhice ancorada nas características da juventude contemporânea. Com base nesses indícios, pode-se supor que a representação social da velhice desse grupo está organizada pelo princípio do contraste; entre jovens e velhos, nós e eles, e as respectivas características, que tencionam a representação na direção mais tradicional ou mais contemporânea.

A outra representação social, do grupo de idosas, também se tenciona entre seu duplo desejo: afastar a solidão, por meio da proximidade com a família, por um lado e por outro, afirmar sua autonomia, sua independência de outras pessoas, fazendo o que gosta, o que quer. Imagens como a do "ninho vazio" ou perdas por morte objetivam a face sombria do envelhecer. $\mathrm{O}$ protagonismo, embora não seja a única expressão forte no grupo, é evidenciado, configurando uma postura nova em relação ao idoso de antigamente, provável indício da mudança em curso na sociedade.

Assim, os grupos pesquisados parecem estar em processo de elaborar esta novidade: a nova velhice. As objetivações do velho como "trapo" e do idoso como aquela pessoa ativa, "antenada" com a tecnologia, distante da figura estereotipada, grisalha e recolhida, indicam nuances na categorização do envelhecimento. Os 
sinais que marcam o corpo envelhecido são vistos como algo que, no futuro, o velho poderá não ter. A tecnologia estará presente para "domar" tais mudanças.

Esses achados confirmam que o velho, a velhice e o envelhecimento são objetos sociais de relevância para a sociedade. A "nova velhice", para os jovens, está apoiada na tecnologia, na mídia. Os idosos "plugados" e "antenados" compõem um novo perfil reforçado pelos canais de comunicação. Essas seriam as sementes da mudança nas representações sociais sobre o envelhecimento em alguns segmentos da sociedade?

Sugerem-se mais pesquisas no campo das representações sociais sobre o tema em grupos etários e sociais diversos. Em particular, buscando identificar e aprofundar a questão da alteridade nas discussões entre idosos e jovens, e perceber como ocorre a comunicação entre eles. $\mathrm{O}$ conhecimento das representações sociais ilumina formas de pensar e de agir com relação ao fenômeno pesquisado, possibilitando o diálogo e a identificação de visões diferenciadas, de respostas diversas diante dele, inclusive as dos interessados, fornecendo mais elementos para pensar políticas públicas e ações de toda ordem voltadas para eles.

Finalizando, destaca-se que os resultados encontrados são contingenciais e limitados, devido ao número reduzido de pessoas pesquisadas e porque, como foi dito, os grupos (idosas do Sesc e alunos do Senac) foram mais expostos a alternativas positivas do envelhecer e podem ter mais abertura para outras representações da velhice. Assim, os resultados encontrados não permitem generalizações.

Espera-se, contudo, que este estudo tenha contribuído para que novas pesquisas venham a dar continuidade à investigação dos processos de permanência e de mudança de representação social sobre o envelhecimento. E que possa inspirar discussões e a forma como as instâncias oficiais têm lidado com a questão, com os anseios e necessidades dos idosos e com o espaço que reservam, em seu interior, para a presença e o protagonismo destes. 


\section{REFERÊNCIAS}

Arruda, A. (2012). Envelhecer: uma novidade? In L. F. R. Tura, \& A. O. Silva (Orgs.), Envelhecimento e representaçôes sociais. (pp. 19-33). Rio de Janeiro: FAPERJ, Quintet.

Beauvoir, S. (1990). A velhice: o mais importante ensaio contemporâneo sobre as condiçôes de vida dos idosos. M. H. F. Martins (Trad.). Rio de Janeiro: Nova Fronteira.

Caldas, C. P. (2006). O autocuidado na velhice. In E. V. Freitas et al. (Orgs.), Tratado de geriatria e gerontologia. (pp. 1117-1130). Rio de Janeiro: GuanabaraKoogan.

Caldas, C. P., \& Veras, R. P. (2012). Saúde do idoso: a necessária abordagem multidimencional. In L. F. R. Tura, \& A. O. Silva (Orgs.), Envelhecimento e representaçôes sociais. (pp. 68-87). Rio de Janeiro: FAPERJ, Quartet.

Camarano, A. A. (Ed.). (2004). Muito além dos 60: os novos idosos brasileiros. Rio de Janeiro: IPEA.

Camargo, B. V. (2005). Alceste: um programa informático de análise quantitativa de dados textuais. In A. Moreira, B. Camargo, J. Jesuíno, \& S. Nóbrega (Orgs.), Perspectivas teórico-metodológicas em representaçôes sociais (pp. 511-539). João Pessoa: UFPB.

Cantarello, A., Leoni, G., \& Wachelke, J. (2012). O envelhecimento em uma sociedade que envelhece. In L. F. R. Tura, \& A. O. Silva (Orgs.). Envelhecimento e representaçôes sociais (pp. 139-167). Rio de Janeiro: FAPERJ, Quartet.

Castro, A. et al. (2016). Representações sociais do envelhecimento e do rejuvenescimento para mulheres que adotam práticas de rejuvenescimento. Psico, 47 (4), 319-330.

Ferreira, M. (2016). Ergonomia do envelhecimento: acessibilidade e mobilidade urbana no Brasil. Ergodesign \& HCI, 4(1), 31-40.

Freitas, M. C., \& Ferreira, M. A. (2013). Velhice e pessoa idosa: representações sociais de adolescentes escolares. Revista Latino-Americana de Enfermagem, 21(3), 1-8.

Gatti, B. A. (2005). Grupo focal na pesquisa em Ciências Sociais e Humanas. Brasília: Liber Livro. 
Gondim, S. M. G (2003). Grupos focais como técnica de investigação qualitativa: desafios metodológicos. Paidéia, 12(24), 149-161. Recuperado a partir de https://www.scielo.br/pdf/paideia/v12n24/04.pdf.

Hillman, J. (2001). A força do caráter: a poética de uma vida longa. E. Sabino (Trad.). Rio de Janeiro: Objetiva.

Jodelet, D. (2001). Representações sociais, um domínio em expansão. In D. Jodelet (Org.), As representaçôes sociais. (pp. 17-44). L. Ulup (Trad.). Rio de Janeiro: EdUERJ.

Kalache, A., Veras, R. P., \& Ramos, L. R. (1987). O envelhecimento da população mundial: um desafio novo. Revista de Saúde Pública, 21(3), 200-210.

Magalhães, N. C. (2007). Máscaras e conflitos da representação social do idoso na cidade de Juiz de Fora. Psicologia em Pesquisa, 1(1), 52-57.

Morgan, D. L. (1997). Focus groups as qualitative research. London: Sage. (Coleção Qualitative Research Methods, 16).

Moscovici, S. (1988). Notes towards a description of social representations. European Journal of Social Psychology, 18(3), 211-250.

Moscovici, S. (2007). Representaçôes sociais: investigaçôes em Psicologia social. P. A. Guareschi (Trad.). Petrópolis: Vozes.

Moscovici, S. (2012). A psicanálise, sua imagem e seu público. S. Fuhrmann (Trad.). Petrópolis: Vozes.

Neri, A. L. (2001). Paradigmas contemporâneos sobre o desenvolvimento humano em Psicologia e em Sociologia. In A. L. Neri (Org.), Desenvolvimento e envelhecimento: perspectivas biológicas, psicológicas e sociológicas. (pp. 11-37). Campinas: Papirus.

Nóbrega, D. O., Andrade, E. R. G., \& Melo, E. S. N. (2016). Pesquisa com grupo focal: contribuições ao estudo das representaçóes sociais. Psicologia \& sociedade, 28(3), 433-441.

Oliveira, D. C., Gomes, A. M. T., \& Marques, S. C. (2005). Análise estatística de dados textuais: alguns princípios e uma aplicação ao campo da saúde. In M. S. S. Menin \& A. M. Shimizu (Orgs.), Experiência e representação social: questôes teóricas e metodológicas. (pp. 157-200). São Paulo: Casa do Psicólogo. 
Pecora, A. R., Anjos, P. M., \& Paredes, E. C. (2010). O envelhecimento como processo social. Revista de Educação Pública, 19(39), 55-73.

Pereira, R. F. (2012). Representaçôes sociais de adolescentes escolares sobre idoso e velhice: subsidios para o cuidado clínico de enfermagem. (Dissertação de Mestrado). Universidade Estadual do Ceará, Programa de Pós-Graduação em Cuidados Clínicos em Enfermagem e Saúde, Fortaleza.

Rabelo, V. R. C. (2014). O envelhecimento em Juiz de Fora-MG: tecendo as representaçôes sociais de grupos de idosos e de adultos jovens e dos jornais locais. (Tese de Doutorado). Universidade Federal do Rio de Janeiro, Programa de Pós-Graduação em Psicologia, Rio de Janeiro.

Rodrigues, N. C., \& Rauth, J. (2006). Os desafios do envelhecimento no Brasil. In E. V. Freitas, \& L. Py (Orgs.). Tratado de geriatria e gerontologia. (pp. 186192). Rio de Janeiro: Guanabara-Koogan.

Santos, V. B., Tura, L. F. R., \& Arruda, A. M. S. (2013). As representações sociais de "pessoa velha" construídas por idosos. Saúde e Sociedade, 22(1), 138-147.

Silva, L. R. F. (2008). Terceira idade: nova identidade, reinvenção da velhice ou experiência geracional? Physis, 18(4), 801-815.

Sousa, C. M., Farias, R. C. P., Doula, S. M., \& Mafra, S. C. T. (2016). Representações sociais sobre o envelhecer e os direitos sociais dos idosos: o caso do programa municipal da terceira idade, Viçosa - Minas Gerais. Oikos: Revista Brasileira de Economia Doméstica, 27(1), 135-156.

Universidade Federal de Juiz de Fora. (2012, 20 dezembro). Pesquisa revela perfil e situação do idoso em Juiz de Fora. Arquivo de Notícias, Juiz de Fora. Recuperado a partir de: http://www.ufff.br/secom/2012/12/20/pesquisa-revela-situacaodo-idoso-em-juiz-de-fora

Wachelke, J. F. R., Camargo, B. V., Hazan, J. V., Soares, D. R., Oliveira, L. T. P., \& Reynaud, P. D. (2008). Princípios organizadores da representação social do envelhecimento: dados coletados via internet. Estudos de Psicologia, 13(2), 107-116. 